\title{
Depression by the Theory of Breathing and Finding Meaning of Life
}

\author{
Nadia Khalid Al-Khalidi' ${ }^{1}$, Hamad Al-Tayyar ${ }^{2}$ \\ ${ }^{1}$ Faculty of Educational Sciences, The World Islamic Science and Education University, Amman, Jordan \\ ${ }^{2}$ College of Social Sciences, Kuwait University, Kuwait City, Kuwait \\ Email: nksalkhalidi@gmail.com, Hamad.altayyar@ku.edu.kw
}

How to cite this paper: Al-Khalidi, N.K. and Al-Tayyar, H. (2021) Depression by the Theory of Breathing and Finding Meaning of Life. Journal of Behavioral and Brain Science, 11, 286-300. https://doi.org/10.4236/jbbs.2021.1112024

Received: October 29, 2021

Accepted: December 14, 2021

Published: December 17, 2021

Copyright () 2021 by author(s) and Scientific Research Publishing Inc. This work is licensed under the Creative Commons Attribution International License (CC BY 4.0).

http://creativecommons.org/licenses/by/4.0/

(c) (i) Open Access

\begin{abstract}
This study aimed to examine the relationship of finding meaning to life with the level of depression and investigates the effect of using breathing theory in treating or reducing depression in a sample of individuals suffering from depression in the Kuwait Mental Health Center. In order to achieve these objectives, the researcher used the descriptive and analytical approach through an applied questionnaire on the study sample which consist of (380) individuals and the quasi-experimental approach by dividing the study sample individuals into two groups; control group consisted of (190) individuals and experimental group consist of (190) individuals. Also, the researcher developed meaning of life scale and breathing strategy, also used beck depression inventory scale. The study found a set of results, there is a negative relationship between finding meaning in life and depression and there are statistically significant differences between the members of the two groups due to the use of the breathing strategy, in favor of the experimental group. In the light of this result, the study came out with a set of recommendations, the most important of which are holding training and educational courses for depressed patients on ways and methods of finding meaning in life, as these courses have the benefit in reducing the level of depression among patients.
\end{abstract}

\section{Keywords}

Depression, Theory of Breathing, Finding Meaning of Life, Kuwait

\section{Introduction}

The current era is characterized as the era of positive and negative psychology, as its interests revolve around different and multiple topics centered around the individual's experiences, and its positive characteristics such as happiness, op- 
timism, confidence, and hope, in addition to concern for the individual's negative emotions and psychological disorders, and these influences are associated with the individuals' emotions and their capabilities.

The individual, in his/her habit, always strives to make every effort to reach a sense of happiness, considering it the desired goal in his/her life in light of the growing challenges and problems, as the changes occurring in the cultural, social, economic and political fields cast a shadow over a person's thinking and planning aspects of his life, which affects him/her and his/her level of happiness through self-realization, a sense of joy and reassurance, and avoiding depression and anxiety [1]. Also, exceeding certain limits of emotions makes the individual in an extreme and urgent state that may reach disease, anxiety and depression sometimes, and even suicide, so the monitoring of our negative feelings is the key to emotional health, as emotional extremism that is dyed with violence and irritation leads to a loss of personal balance, therefore taking care to balance our feelings is an essential task in our life and it is an essential life skill that everyone should learn [2].

Many mental diseases that may affect a person, some of the psychological and some nervous, and depression is one of these diseases, depression is one of the most prevalent mental diseases at the present time, and scientific studies confirm a high incidence of it in the future, depression is a disease that negatively affects the way of thinking and behaving. Also, depression affects males and females alike, the young, the old, and the elderly do not differentiate between the level of education and culture and the material level, so everyone is vulnerable to it [3].

On the other hand, the concept of the meaning of life is a popular and multi-responsive concept that describes life experiences that have meaning, value and purpose, as it is important to have meaning in human life. With life meaning, a person feels his/her value and humanity, accepts life, interacts and responds to it, and achieves distinction and uniqueness and striving to achieve his/her goals, while with the lack of life meaning a person becomes troubled, full of many psychological problems and disturbances, and may even have thoughts of suicide and getting rid of life, just as man differs in the way he/she achieves meaning in his/her life according to his/her intellectual affiliations and philosophical doctrines [4].

The meaning of life differs from one person to another; as there is no fixed meaning of life for any individual, rather it represents a person's special meaning about his/her life at a specific time, and the meaning of life is not relative, but unique and different, according to (Francle), who pointed out that each person has a unique opportunity to discover a very special meaning of his/her life [5].

The meaning of life includes various sources, and these sources may be personal relationships, activities, innovations, economic safety, or various cultural values and customs, where helping others is one of the sources of creating the meaning of life. Therefore, we find that the meaning of life varies from one age stage to another, as the meaning of life among the elderly is concentrated in the 
family, children and grandchildren, in comparison with adults [1].

Francle was one of the first to take an interest in the term meaning of life. As this idea was born to him through his suffering with a group of detainees in the concentration camps in Vienna after the Second World War, he saw that the meaning of life is a product of the circumstances and factors surrounding the individual, as it does not exist by questioning the goal or purpose of life, but it appears through the individual's responses to the situations and demands that he faces in life [6].

According to the breathing method, human beings breathe to live. Since ancient African times, this vital link between breath and life has provided the foundation for various religions, philosophies, beliefs and practices related to survival, meaning, preservation and promotion of life in this world and in the afterlife. In its original, essential and literal meaning, psychology is concerned with the breath, energy, consciousness, soul or spirit of life that leaves a person at death and continues in some other form [7].

The current study represents a purposeful attempt to contribute to the knowledge of the relationship that binds the meaning of life for individuals with depression, as this topic is of great importance in trying to identify how to reduce the spread of depression. The importance also stems from the sample covered by the study, which are individuals who suffer from depression in Kuwait, as this group needs a lot of attention and study to know what they suffer and how to help them. It may benefit learners and those interested in the field of providing services to this group, and it may increase the balance of knowledge of their needs and requirements, and the findings of the study may contribute to the development of counseling programs to help individuals with depression; By providing specific services that improve their quality of life and improve their lives, and counselors interested in this category may also benefit from them.

Drawing on what was previously discussed; this study seeks to try to find the relationship between finding meaning in life and depression on the one hand, and on the other hand, the relationship of depression with the theory of breathing.

\section{Research Problem}

Depression is a disease that afflicts a person, which causes him to suffer from a set of symptoms, such as lack of enjoyment of the joys of life, sleep disturbances, and may be in the form of difficulty or a lot of sleep, and depression is a feature of the modern era, as it is the result of the secretions of complex interactions of civil elements, technological development, political, economic, social and security circumstances, so the concept of depression attracts the interest of many researchers and scholars on this subject in its various branches, as many individuals are exposed to many pressures that cause them depression.

On the other hand, many studies have indicated [2] [8] that finding the meaning of life in individuals is affected by many circumstances. This causes them to view life in a negative light. Because of the many pressures placed on 
them, and the nature of their difficult work, which causes a change in the individual's perception of himself/herself and those around him/her. In Kuwait, a report issued by the Kuwaiti Ministry of Health for the year 2020 indicated that there are about one million and 250 thousand people suffering from depression, as the Kuwait Center for Mental Health alone supervises about $(68,740)$ files of mental patients, most of whom are depressed.

Therefore, it is necessary to try to find positive influences that limit the prevalence of depression in Kuwaiti society, and this is what the study came for, as it is considered an attempt to reveal the extent to which depression is affected by finding the meaning of life on the one hand, and on the other hand in revealing the effect of using the method Respiration can relieve and reduce the symptoms of this disease, and accordingly, this study seeks to answer the following two questions:

1) What is the relationship of finding meaning to life with the level of depression of a sample of individuals suffering from depression in the Kuwait Mental Health Center?

2) What is the effect of using breathing theory in treating or reducing depression in a sample of individuals suffering from depression in the Kuwait Mental Health Center?

\section{Literature Review}

\subsection{Depression}

Depression is considered a state of intense and continuous sadness as the person suffering from it remains in permanent mourning, and depression is clear on the features of his face as a result of his sad circumstances, and the patient may not be aware of the true source of his sadness, and the person with depression may imagine that he is suffering from fatal diseases, no hope of curing them [9]. Depression is also a term used to describe a mixture of pathological or non-pathological conditions in a person that is predominantly characterized by sadness, and there are multiple types of depression that are divided according to the length of the period of sadness or according to the effect of sadness on the social and professional life of the individual, or according to the episodes of joy that accompanies sadness or depression [10].

In addition to that depression leads to a decrease in morale and effort, a feeling of loss, loss of hope and uselessness, which is an extreme and inappropriate emotional response to the exciting event, as it differs from sadness in terms of intensity and duration of the response, and the depressed cannot sense the joyful feelings unlike the one who suffers from the state of sadness, and the patient with depression tends to ruminate unpleasant thoughts and experiences in his/her life [11].

The researcher believes that depression is a psychological disease that makes the person afflicted with it regret the past and think about it a lot, as the person with depression always tries to search for ills and causes, which causes him to 
have a great void that makes him unable to perform his tasks properly.

There is a group of symptoms that afflict a depressed patient, which can be classified as follows:

Physical symptoms: A person with depression suffers from conditions that can be considered physical symptoms, such as: constriction in the chest and a feeling of malaise, loss of appetite and refusal of food due to the patient's feeling that the patient does not deserve him or her desire to die, weight loss, constipation and fatigue for the least effort, body pain, especially in the back, poor general activity psychomotor delay, slow and monotonous movement, delusion of disease, preoccupation with health, sleep disturbance, menstrual disturbance for women, and depression on the external appearance [12].

Psychological symptoms: A person with depression exhibits a set of psychological symptoms such as: misery and despair, grief, low spirits, sadness that does not match its cause, mood deviation and volatility, inability to self-control, poor self-confidence, feelings of inadequacy and worthlessness and insignificance, anxiety, tension and insomnia Introversion, withdrawal, loneliness and isolation, stillness and silence, distraction until stupor, pessimism and disappointment of pain, black outlook on life and black thoughts, belief that there is no hope for healing, engaging in crying sometimes, inability to enjoy the joys of life, indifference and lack of tendencies, interests and motivation, neglect of hygiene And personal appearance, slow thinking and response, difficulty concentrating and hesitation, slow and lack of speech and low voice, accusation and self-accusation and amplify its mistakes, and sometimes suicidal thoughts, and hallucinations [13].

General symptoms: the most important of which are lack of production, lack of enjoyment of life and poor social harmony, and despite the different concepts and theoretical trends that examined depression, they agree that there are common signs and symptoms of depression, and the clinical diagnosis is made according to the presence of some of them, especially the deep sadness and apparent unhappiness that inconsistent with the patient's life conditions [14].

\subsection{Finding Meaning of Life}

The meaning of life represents one of the variables affecting the behavior of the individual according to the perspective of personality psychology, it is not possible to imagine an individual living in psychological health, happiness and effectiveness without realizing that his/her life has meaning in this existence, and that he/she has the task of striving to reveal this meaning [2].

The political and social events prevailing in Europe in the nineteenth century played a role in the emergence of new currents in psychology and psychological therapies, on top of which appeared the theory of treatment in the sense developed by Francle, whose main goal is to help people find meaning in their lives and try to achieve that meaning [15].

The subject of the meaning of life is among the existential concerns of the in- 
dividual, as some researchers such as (Adamson and Lyxell) who indicated that the existential interests of the individual begin especially in the stage of adolescence, which revolve mostly around the future, death, religion, and the philosophy of life. Also, adolescents without psychological loneliness problems chatted with adults about existential issues and ideas related to the meaning of life [16].

Francle in 1950 considered the first to refer to this concept as the basic and essential motivation of the individual, until he considered it the central concept in his theory of the human personality. Francle was initially influenced by Freudian analysis when explaining human behavior, but he soon switched to existential concepts believing in the imperfection of psychoanalysis, the person from his point of view is more than a mere psychological apparatus governed by his pent-up lustful instincts [6].

The meaning of life defines as that concept presented by Francle within the foundations of his theory of meaning therapy, and indicates that life has meaning under all circumstances and factors, and the concept of the meaning of life appeared within the system of concern for the human direction in psychology, which is concerned with studying the individual as a spiritual experience, in addition to being a biological structure subject to growth, change and sublimation [5].

While [4] defines it as the special meaning of the individual, which is determined by his orientations towards his life and his special message in life or his profession, which offers him specific tasks that must be achieved, and the meaning of life is not achieved through self-realization only, but that must be transcended abroad; where a relationship is made with the other and something of value is presented to the other.

Francle's theory is based on his criticisms of both Freudian psychoanalysis and Adlerian psychology, as Francle believes that the Freudian pleasure principle and the Adlerian position drive are insufficient to explain human behavior, and in this regard he decides to set what he called the principle of will the meaning is to be opposed by both the Freudian principle of pleasure and the principle of the will to power in Adlerian psychology, where the pursuit of pleasure or the attainment of the dominant position to obtain power and influence cannot explain all forms of human activity, while the meaning of life for every human being is what it can make persistent striving and enduring suffering something that raises the value of life and makes it worth living [17].

\subsection{Theory of Breathing}

Breathing exercises are a great way to make the individual more in touch with your mind, body and soul, where intentional deep breathing (yoga-based breathing) can be used as a way to maintain the psychological state, and intentional breathing can also be used to express feelings of anger, especially the uncomfortable feelings that the individual is trying escape from them [18].

[19] indicated that during moments of stress, intentional breathing allows negative energy to be exchanged and released rather than stored within the body. 
This is important because the stored energy often manifests itself in the form of muscle tension and other physical disturbances. Breathing training has other benefits as well. It may increase the ability to pay attention and oxygen flow and allow your body to release toxins more easily. Although breathing is something the body does naturally, it is also a skill that can be strengthened.

Breathing is intimately linked with mental functions. In the millenary eastern tradition, the act of breathing is an essential aspect of most meditative practices, and it is considered a crucial factor for reaching the meditative state of consciousness, or "Samadhi" (Patanjali, Yoga Sutras). The breath is called "Prana," which means both "breath" and "energy" (i.e., the conscious field that permeates the whole universe). "Prana-Yama" (literally, "the stop/control," but also "the rising/expansion of breath") is a set of breathing techniques that aims at directly and consciously regulating one or more parameters of respiration (e.g., frequency, deepness, inspiration/expiration ratio). Pranayama is primarily related to yoga practice, but it is also part of several meditative practices [2].

\section{Methodology}

To reach the desired goals of this study, the descriptive and analytical approach was used through describing the characteristics of the phenomenon studied, collecting information about it and following it up in the field in order to obtain real data, achieve its objectives and answer the study questions. The quasi-experimental approach was also used by dividing the study sample individuals into two control and experimental groups.

\subsection{Study Population}

The study population consisted of all individuals who suffering from depression at the Kuwait Center for Mental Health, which total $(35,520)$ patients.

\subsection{Study Sample}

The sample comprised (380) patients that selected in randomly way from total of depression patients at the Kuwait Center for Mental Health, for apply the study instruments, where the researcher chooses this sample depend on [20] [21].

Table 1 shows the distribution of the study sample according to their demographic variables.

\subsection{Study Instrument}

The researcher in the current study relied on the questionnaire as a main tool for collecting data; in addition, the researcher used breath-work approach to train the patients in the experimental group, in order to try to discover the effect of breathing on their level of depression.

\section{A Measure of Finding Meaning}

The meaning of life scale has been prepared and includes special dimensions for the meaning of life. It is characterized by a few questions that take a few 
Table 1. Characteristics of the study sample according to the demographic variables.

\begin{tabular}{clcc}
\hline \multirow{2}{*}{ Variable } & \multicolumn{1}{c}{ Categories } & Frequency & Percentage \% \\
\hline \multirow{3}{*}{ Gender } & Male & 205 & $53.9 \%$ \\
& Female & 175 & $46.1 \%$ \\
& Total & 380 & $100 \%$ \\
\hline \multirow{2}{*}{ Age } & $20-29$ years & 92 & $24.2 \%$ \\
& $30-39$ years & 112 & $29.5 \%$ \\
& $40-49$ years & 146 & $38.4 \%$ \\
& 50 and above & 30 & $7.9 \%$ \\
& Total & 380 & $100 \%$ \\
\hline \multirow{2}{*}{ Job } & Government Sector & 174 & $45.7 \%$ \\
& Private Sector & 106 & $27.9 \%$ \\
& Student & 12 & $3.2 \%$ \\
& Unemployed & 88 & $23.2 \%$ \\
& Total & 380 & $100 \%$ \\
\hline
\end{tabular}

minutes to answer, and are within the culture of the society to which the research sample belongs. The scale consists of (15) paragraphs that measure the following dimensions: (life goals, motivation in life, and bearing responsibility), and the respondent answers them with four choices (never, rare, sometimes, and always).

\section{Beck Depression Inventory}

It is a self-test consisting of 20 multiple choice questions, which measures characteristic situations and symptoms of depression, and each group of questions is concerned with one of the symptoms of depression.

\section{Breath-work Approach}

The breath-work technique described here involves therapists guiding clients through an approximately one-hour process involving the ongoing regulation of breathing, relaxation and application of mindfulness, while the client lies comfortably on their back. A series of ten weekly or fortnightly sessions is the suggested norm. Apart from providing a rationale for the approach and general support, no additional cognitive or behavioral strategies are required.

To apply the breathing strategy, the researcher resorted to using diaphragmatic breathing, which is a great way to reduce stress, and this strategy included the following exercises:

1) Get a comfortable position. Close your eyes and focus your attention on your body and your breath.

2) Inhale deeply through the nose, allowing it to fill your abdomen with air, and gently expanding it. Exhale by relaxing and releasing all the air through the nose. 
3) Place one hand on your stomach, just below your navel, and with the other hand on the top of your chest. Take a deep breath through your nose and exhale through your nose. Feel the coolness of the air entering it and the warmth as it flows out.

4) When you breathe in and out of the nose, focus on alternating your breaths until you feel more and more in your stomach than in your chest, in other words, let the hand resting on your stomach move more than the hand on your chest. Take a deep breath through your nose, and send it through the back of your throat and into your stomach. Let your belly contract slowly as the breath exits the nose.

5) Take three slow, deep breaths with conscious focus on the rise and fall of the abdomen. Continue to breathe fully and deeply, allowing the body to be confident as the breathing slows down and becomes more relaxed.

\section{Data Source and Analysis}

The objective of data collection is to provide the basic platform for research or projects to achieve the desired goal of their existence. Therefore, the current study followed a set of steps in order to collect the suitable data for it. The researcher relied on two sources of data in this study:

Primary sources: They are also referred to as field sources, which are directly related to the subject of the study. The data of the study community are collected directly, through the questionnaire.

Secondary Sources: Data collected by the researcher from periodicals, books and reports, as well as master's thesis, doctoral dissertations and other reliable sources.

For the analysis of the study, data will be analyzed with Statistical Package for the Social Sciences software (SPSS. 25), through:

1) The descriptive statistics (frequency, percentage, arithmetic mean and standard deviation).

2) T-test for two independent samples.

\section{Study Results}

The first question: What is the relationship of finding meaning to life with the level of depression of a sample of individuals suffering from depression in the Kuwait Mental Health Center?

To answer this question, the researcher extracted the Pearson correlation coefficient between finding meaning in life in its dimensions (life goals, motivation in life, and bearing responsibility) and depression, and Table 2 Illustrates the results of that.

It is clear from Table 2 that all the correlational relationships are negative and statistically significant, and at negative levels between the independent variables represented by finding meaning in life, and depression as a dependent variable, whether at the macro level or at the one-dimensional level, and the total value of 
Table 2. Demonstrates the matrix of the Pearson correlation coefficient of the correlation between finding meaning in life in its dimensions (life goals, motivation in life, and bearing responsibility) and depression.

\begin{tabular}{ccc}
\hline \multirow{2}{*}{ Independent variables } & \multicolumn{2}{c}{ Depression } \\
\cline { 2 - 3 } & Correlation coefficient & Sig. \\
\hline life goals & $-0.373^{* *}$ & 0.000 \\
motivation in life & $-0.494^{* *}$ & 0.000 \\
bearing responsibility & $-0.491^{* *}$ & 0.000 \\
Finding Meaning & $-0.536^{* *}$ & 0.000 \\
\hline
\end{tabular}

${ }^{* *}$ Correlation is significant at the 0.01 level.

the correlational relationship between finding meaning in life and depression as a whole $(-0.536)$, which is a negative value that confirms the effect of finding meaning in depression, and the strongest of these relationships was with the dimension of (motivation in life), as the strength of this correlational relationship reached $(-0.494)$, while the weakest of these relationships was the relationship with the dimension (life goals), where the value of this correlational relationship was $(-0.373)$.

The researcher attributes this result to the fact that finding the meaning of life represents one of the variables affecting individual behavior according to the perspective of personality psychology. It is not possible to imagine an individual living in psychological health, happiness and effectiveness without realizing that his life has meaning in this existence, and that he has the task of striving to reveal this meaning.

This result may be attributed to the fact that when a person has meaning in his/her life and is able to satisfy his/her basic needs in conjunction with his/her awareness of the quality of life during his/her passage of experiences, that is satisfaction with life, and the individual's self-satisfaction increases the more he/she thinks about life situations in a positive way, which is undoubtedly linked to many important psychological variables such as happiness, hope, sense of responsibility, and awareness of the meaning of life.

The second question: What is the effect of using breathing theory in treating or reducing depression in a sample of individuals suffering from depression in the Kuwait Mental Health Center?

To ensure the validity of the study results and avoid any other factors that may affect this study, in addition to the possibility of generalizing the results that will be reached, the researcher carried out a set of tests for the members of the study sample in its two parts (experimental group and control group) in order to ensure that the two study groups are equal, as this is all done before starting to use a breathing strategy, as follows:

The equivalence of the members of the two study groups (experimental and control) in the depression scale prepared for this study, and this was done by 
applying the depression scale to the members of the two study groups before using the breathing strategy, then the results were collected for all the study sample members and a T-test was performed for the results of the two groups, and Table 3 Explains the results of this.

Noted from Table 3 that the means of the experimental group in the depression scale is (3.23) with a standard deviation of (0.269), while the means of the control group is (3.24) and a standard deviation (0.266), as indicated by the value of $(\mathrm{T})$ of (0.057) and the level of significance $(0.844)$ that mean there are no statistically significant differences at the level of significance $(\alpha \leq 0.05)$ between the means of the experimental and control groups in the depression scale, which indicates the parity of the two groups and their suitability for the purposes of the study, and this means that if there are statistically significant differences after using the breathing strategy, the causes are attributed to this strategy.

To answer this question, the arithmetic means, standard deviations, and ( $\mathrm{t}$ ) test of two independent samples were extracted to indicate the differences between the performance of the experimental group and the control group on the depression scale prepared in this study after training the experimental group members through the breathing strategy, and the control group members were not trained, and Table 4 Explain the results of this.

Noted from Table 4 that the means of the experimental group in the depression scale is (2.73) with a standard deviation of (0.269), while the means of the control group is (3.33) and a standard deviation (0.269), as indicated by the value of $(\mathrm{T})$ of (21.737) and the level of significance (0.000) that mean there are statistically significant differences at the level of significance $(\alpha \leq 0.05)$ between the means of the experimental and control groups in the depression scale, which indicates the inequality between the two groups, and this means that there are statistically significant differences between the members of the two groups due to the use of the breathing strategy, and this indicates a positive effect of using the breathing strategy on reducing the level of depression among the members of the study sample.

Table 3. T-test results between experimental group and control group members in depression scale before starting to use breathing strategy

\begin{tabular}{ccccccc}
\hline Groups & Frequency & Means & St. Deviation & T value & Sig. & Result \\
\hline Experimental & 190 & 3.23 & 0.269 & & & Not \\
Control & 190 & 3.24 & 0.266 & & & Significant \\
\hline
\end{tabular}

Table 4. T-test results between experimental group and control group members in depression scale after starting to use breathing strategy.

\begin{tabular}{ccccccc}
\hline Groups & Frequency & Means & St. Deviation & T value & Sig. & Result \\
\hline Experimental & 190 & 2.73 & 0.269 & & & \\
Control & 190 & 3.33 & 0.269 & & & \\
\end{tabular}


The researcher attributes this result to the benefits of deep breathing in relieving pressure in individuals, as deep breathing based on yoga helps to balance the autonomic nervous system, which regulates involuntary body functions, such as temperature control and bladder function, and this may help relieve symptoms of disorders associated with stress and mental health conditions such as anxiety, general stress, depression and post-traumatic stress disorder.

The researcher also attributes this result to the fact that one of the benefits of deep breathing exercises is to help get rid of disturbed emotions, replace them with comfort and relaxation, and reject feelings of sadness and depression. This indicates that breathing and relaxation exercises are essential for human health, as they play a major role in overcoming psychological and physical problems. All this indicates that the use of breathing strategy reduces the level of depression in individuals.

\section{Conclusions}

Depression is one of the most common mental disorders. It is classified as a psychological disorder characterized by an imbalance in the mood of the individual, and depression mainly affects the emotional sphere of individuals, such as permanent sadness, the desire to cry, irritability, irritability and anxiety. The most important characteristic of depression is the gradual-or acute and sometimes accelerated-decrease in mood and aversion to activities. Therefore, it is necessary to find more effective ways and means to reduce this disease and try to eliminate it.

Hence, this study came with the aim at examine the relationship of finding meaning to life with the level of depression and investigates the effect of using breathing theory in treating or reducing depression in a sample of individuals suffering from depression in the Kuwait Mental Health Center.

The study results indicated that there is a negative relationship between finding meaning in life and depression, that's mean when individuals have a good meaning in life they will not suffer from depression. As individuals who find the meaning of life always have a goal that they strive to achieve and work for, so they work hard in their work and constantly try to achieve their goals, and this negatively affects their level of depression.

Also, realizing the meaning of life helps to improve the physical, mental and cognitive functions of individuals, which makes them realize the meaning of their lives with greater happiness and better health than others, and this is what makes them always optimistic and happy, and thus the rate of depression becomes difficult if not non-existent.

This result is also attributed to the fact that the individuals need to have meaning in their life, through the presence of will and freedom for him to search for this meaning, as the absence of meaning in an individual's life makes his/her life empty and empty from three aspects: the existence itself, i.e., the distinctive way of being for individual, the meaning of existence, and the pursuit of a tangi- 
ble meaning in personal existence, that is, the will of meaning. Therefore, a person must strive and strive for a goal that he deserves to live for, as this helps him/her stay effective even in the worst conditions. All of this may have a positive effect on lowering the level of depression in individuals.

In addition, the study results showed that there are statistically significant differences between the members of the two groups due to the use of the breathing strategy, in favor of experimental group. This result may be attributed to the fact that deep breathing exercises are one of the best techniques for solving many psychological and physical problems, due to their ability to give a person a feeling of relaxation and comfort, where when a person is tense, he puts pressure on his body, and he feels anger, anxiety and fear at the same time, which makes his heartbeat accelerate. Therefore, it is good to practice deep breathing exercises to relax and to get the greatest possible rest, to regulate the heartbeat, and to get rid of the feeling of anger, fear and anxiety, which helps reduce tension significantly.

The researcher points out that breathing exercises are a great way to make individuals more in touch with their mind, body and spirit, and deep, intentional breathing (yoga-based breathing) can be used as a way to keep individuals in the same state. Deliberate breathing can also be used to express feelings of anger, especially uncomfortable feelings; all of this greatly helps individuals get rid of sadness and psychological disorders, which contributes to reducing their incidence or suffering from depression.

\section{Recommendations}

In the light of the results, the study recommended and suggested the following:

1) Holding training and educational courses for depressed patients on ways and methods of finding meaning in life, as these courses have the benefit of reducing the level of depression among patients.

2) The importance of the belief of officials in the Kuwait Center for Mental Health in adopting policies and preparing awareness programs based on the use of breathing strategy in the treatment of depression.

3) Conducting other research and studies on the topic of finding meaning and breathing strategy, and their impact on other mental illnesses such as anxiety.

\section{Acknowledgements}

The authors would like to thank the anonymous referees for constructive comments on the earlier version of this paper.

\section{Conflicts of Interest}

The authors declare no conflicts of interest regarding the publication of this paper.

\section{References}

[1] Brown, P. (2009) Quality of Life and Affect across the Adult Life Span. Cambridge 
University Press, New York.

[2] Bradley, H. and Esformes, J.D. (2014) Breathing Pattern Disorders and Functional Movement. International Journal of Sports Physical Therapy, 9, 28-39.

[3] Kleftaras, G. and Psarra, E. (2012) Meaning in Life, Psychological Well-Being and Depressive Symptomatology: A Comparative Study. Psychology, 3, 337-345. https://doi.org/10.4236/psych.2012.34048

[4] Holland, J. (2017) Finding Meaning in the Face of Life Difficulties. How to Live Well and Wisely, 215-219.

[5] Hamidi, S., Yetkin, A. and Yatkin, Y. (2010) The Meaning of Life: Health, Disease, and the Naturopathy. International Journal of Psychology and Counselling, 2, 9-16.

[6] Chagas, L.C.D., Credential, A. and Graber, A.V. (2003) The "Ultimate Meaning" of Viktor Frankl. Victor Frankl Institute of Logo Therapy, 33 p.

[7] Lalande, L., Bambling, M., King, R. and Lowe, R. (2012) Breathwork: An Additional Treatment Option for Depression and Anxiety? Journal of Contemporary Psychotherapy, 42, 113-119.

[8] Sedikides, C. and Wildschut, T. (2017) Finding Meaning in Nostalgia. Review of General Psychology, 22, 1-21. https://doi.org/10.1037/gpr0000109

[9] Hashem, Z. (2020) The Meaning of Life and Its Relationship to Depression among a Sample of University Students. Journal of Damascus University, 36, 303-330.

[10] Harlow, L.L., Newcomb, M.D. and Bentler, P.M. (1986) Depression, Self-Derogation, Substance Use, and Suicide Ideation: Lack of Purpose in Life as a Mediational Factor. Journal of Clinical Psychology, 42, 5-21.

https://doi.org/10.1002/1097-4679(198601)42:1\%3C5::AID-JCLP2270420102\%3E3.0 .CO;2-9

[11] Otte, C., Gold, S.M., Penninx, B.W., Pariante, C.M., Etkin, A., Fava, M., Mohr, D.C. and Schatzberg, A.F. (2016) Major Depressive Disorder. Nature Reviews Disease Primers, 2, Article No. 16065. https://doi.org/10.1038/nrdp.2016.65

[12] Whooley, M.A. and Wong, J.M. (2013) Depression and Cardiovascular Disorders. Annual Review of Clinical Psychology, 9, 327-354. https://doi.org/10.1146/annurev-clinpsy-050212-185526

[13] Li, M., D’Arcy, C. and Meng, X. (2016) Maltreatment in Childhood Substantially Increases the Risk of Adult Depression and Anxiety in Prospective Cohort Studies: Systematic Review, Meta-Analysis, and Proportional Attributable Fractions. Psychological Medicine, 46, 717-730. https://doi.org/10.1017/S0033291715002743

[14] Arrindell, W.A., Steptoe, A. and Wardle, J. (2003) Higher Levels of State Depression in Masculine than in Feminine Nations. Behaviour Research and Therapy, 41, 809-817. https://doi.org/10.1016/S0005-7967(02)00185-7

[15] Muzio, G. (2006) Theism and the Meaning of Life. Ars Disputandi, 6, 128-139. https://doi.org/10.1080/15665399.2006.10819914

[16] Frisch, M. (2006) Quality of Life Therapy: Applying a Life Satisfaction Approach to Positive Psychology and Cognitive Therapy. John Wiley \& Sons, Inc., Hoboken.

[17] Haugan, A. (2014) Hope and the Meaning of Life. Asia Pacific Education Review, 6, 143-152.

[18] Perciavalle, V., Blandini, M., Fecarotta, P., Buscemi, A., Di Corrado, D., Bertolo, L., Fichera, F. and Coco, M. (2017) The Role of Deep Breathing on Stress. Neurological Sciences, 38, 451-458. https://doi.org/10.1007/s10072-016-2790-8

[19] Malátová, R., Bahenský, P., Mareš, M. and Rost, M. (2017) Breathing Pattern of 
Restful and Deep Breathing. International Journal of Sports Physical Therapy, 9, 28-39.

[20] Aburumman, O., Salleh, A., Omar, K. and Abadi, M. (2020) The Impact of Human Resource Management Practices and Career Satisfaction on Employee's Turnover Intention. Management Science Letters, 10, 641-652. https://doi.org/10.5267/j.msl.2019.9.015

[21] Zamanan, M., Alkhaldi, M., Almajroub, A., Alajmi, A., Alshammari, J. and Aburumman, O. (2020) The Influence of HRM Practices and Employees' Satisfaction on Intention to Leave. Management Science Letters, 10, 1887-1894.

https://doi.org/10.5267/j.msl.2019.12.030 